\title{
The Market Potential of a Grape Pomace Microemulsion
}

\author{
Daniel Lambert ${ }^{1}$, Michel Rod $^{2}$, Christine Dobbin ${ }^{3} \&$ Farah Hosseinian ${ }^{1,4}$ \\ ${ }^{1}$ Department of Chemistry, Carleton University, Ottawa, Ontario, Canada \\ ${ }^{2}$ Sprott School of Business, Carleton University, Ottawa, Ontario, Canada \\ ${ }^{3}$ Christine Dobbin, R\&D coordinator, Bayview Flowers Ltd. Jordan Station, ON \\ ${ }^{4}$ Institute of Biochemistry, Carleton University, Ottawa, Ontario, Canada \\ Correspondence: Farah Hosseinian, Department of Chemistry, Carleton University, Ottawa, Ontario, Canada. \\ E-mail: farah.hosseinian@ carleton.ca
}

Received: January 16, $2016 \quad$ Accepted: November xx, $2016 \quad$ Online Published: March 6, 2017
$\begin{aligned} & \text { doi:10.5539/jfr.v6n2p65 } \\ & \text { URL: https://doi.org/10.5539/jfr.v6n2p65 }\end{aligned}$

\begin{abstract}
Canada's food waste reached $\$ 31$ billion in 2014. 95\% of this waste ended up in landfills across the country, being a severe burden both economically and environmentally. By implementing sustainable agriculture projects, alternative uses can be found for food waste that produce positive income for companies, and alleviate stresses on the environment. Grape pomace, a food waste produced through the process of wine-making, currently ends up in landfills after wine-production. However, this agricultural by-product holds great market potential for the production of chemical microemulsions. These microemulsion systems show great potential in the food, pharmaceutical and cosmeceutical industries. The market potential was calculated by determining the volume of grape seed oil that could be extracted from grape pomace. The current market value of microemulsion surfactants were then obtained and a value was calculated based on the oil yield. Grape pomace microemulsions had the highest market potential as pharmaceutical raw ingredients, followed respectively by food additive and cosmeceutical raw ingredients. The purpose of this paper is to measure the market potential for grape pomace microemulsions in each of these industries and to provoke further investigations into the production of value added products from agricultural waste.
\end{abstract}

Keywords: microemulsion, grape pomace, waste, market potential

\section{Introduction and Background}

\subsection{Food Waste}

Food waste is a growing threat that continues to affect not only Canada but the entire global market, causing significant economic and environmental impacts. Food waste is defined as any food or edible material (liquid or solid) that is produced or used in production (by-products of food production) that is lost throughout the food chain prior to human consumption (Parfitt et al, 2010). In 2014, Canada's quantifiable food waste was estimated to be approximately $\$ 31$ billion, and according to the United Nations Food and Agricultural Organization, this represents only $29 \%$ of the true food waste costs (VCM-International, 2014). More importantly, from an environmental standpoint, $95 \%$ of all global food waste ends up in landfills around the world, which is then broken down into methane, carbon dioxide and other detrimental greenhouse gases through anaerobic digestion (Melikoglu et al, 2013). This chemical breakdown poses a significant threat to the planet and will continue to increase as the amount of food waste increases. According to the United Nations Food and Agricultural Organization, food production must increase by $70 \%$ by 2050 in order to accommodate the increasingly growing population (United Nations FAO, 2016). Many food production systems produce a large amount of waste through the production of by-products, which are eventually deposited into landfills. Many of these waste products hold potential to produce energy through anaerobic digestion, and can also be modified to produce other value added products. According to VCM International, businesses can reduce their operating costs by up to $20 \%$ and increase their profitability by up to $11 \%$ if they implement systems to reduce food waste.

\subsection{Anaerobic Digestion System}

Based on the large amount of grape pomace that is available world-wide, it is clear that there is a market potential for the use of this waste product for energy production and value added products. 
The process of anaerobic digestion has become increasingly popular in the agricultural market for the breakdown of organic waste products and production of "clean" and sustainable energy. Through the process of anaerobic digestion, organic matter (in this case grape pomace) is broken down through bacterial fermentation in the absence of free oxygen, to produce biogas. This biogas is a mixture of methane and carbon dioxide in a 3:1 ratio. The production of this biogas has great appeal to the environment as it has been deemed as "clean" fuel (Abbasi et al, 2012). In order to break down this organic matter, the use of an anaerobic digestion system (ADS) must be implemented.

The overall chemical process of anaerobic digestion requires four different chemical steps. First, the organic matter undergoes hydrolysis, which breaks down the organic waste particulates such as pectin, cellulose, hemicellulose, fat, protein, and sugars into amino acids, alcohols, sugars and long chain fatty acids. Next, the products of hydrolysis undergo acidogenesis, which produces hydrogen gas, carbon dioxide and intermediary compounds such as organic acids and alcohol. These intermediary compounds are then further converted to hydrogen gas, carbon dioxide and acetic acid through the process of acetogenesis. Finally, the reactants are converted to methane and carbon dioxide through the consumption of hydrogen gas by methanogenic bacteria (Bouallagui et al, 2005) It must be noted that this process is a natural chemical reaction that can happen spontaneously in nature, assuming the surrounding conditions allow for such reactions. Temperature, $\mathrm{pH}$, particle size and composition all play a large role in the degree of digestion (Bouallagui et al, 2005). However, over the past decade, the use of anaerobic digestion systems has allowed the agricultural community to simulate the optimal conditions to induce this reaction and capture methane and carbon dioxide products. This capture of gases allows for the production of energy through the burning of the gases. This is considered a "clean" fuel because the carbon that is being released into the atmosphere after combustion of the gases (although considered a greenhouse gas) was originally removed from the atmosphere by the plant. It is part of a carbon cycle and makes the entire process of anaerobic digestion ideally a carbon neutral process (Dai et al, 2015). Therefore, production facilities that implement anaerobic digestion systems will drastically reduce energy production costs, and the environment will benefit by reducing the amount of greenhouse gas emissions and reducing the need for fossil fuels.

\subsection{Grape Pomace as a Value-Added Product}

As stated earlier, food waste that ends up in landfills has many negative economic and environmental impacts, and represents a large missed opportunity for energy production and the production of value added products. Grape pomace is the waste by-product of wine making. After grapes are pressed to extract the juice for wine-making, wine-makers are left with a slurry paste-like product called pomace which consists of the grape's skin, seeds and stems (Yu and Ahmedna, 2013). Like many other agricultural by-products, researchers have found that this waste contains an abundance of value-added ingredients that can be used in many applications.

Grape seed oil (which can be extracted from the seeds found in the pomace) has already begun to appear in a wide variety of food and cosmetic products (Duba and Fiori, 2015). The oil contained within the seeds of grape pomace also shows great market potential within the food and cosmetic industries. $16.3 \%$ of the grape pomace seed is oil. By extracting this oil through supercritical $\mathrm{CO}_{2}$ extraction, a non-toxic, all natural oil can be extracted and sold as a cooking oil. According to Dywer et al, the market potential of this cooking oil in Canada was $\$ 5,047,422$ in 2011 . This oil has great consumer appeal since it is a non-hydrogenated, natural alternative to conventional vegetable oils on the market today. Grape seed oil has become a prominent ingredient in many cosmetic oils. Sephora and Ulta Beauty, two of North America's largest cosmetic retailers both carry products containing grape seed oil with 27 and 20 products respectively in their online markets (Sephora, 2016)(Ulta, 2016). Grape seed oil is also being added to many commercial food products to increase their antioxidant concentration (Maier et al, 2009)(Dywer et al, 2014).

Adding grape seed extracts to food has also been shown to display antimicrobial, ant-carcinogenic and anti-inflammatory properties, all which help to improve the food's overall safety (Perumalla and Hettiarachchy, 2011). In a review by Dywer $e t a l$, the market potential of grape pomace as a value added product was calculated. Grape pomace contains many phenolic compounds that can be categorized into flavonoids and non-flavonoids. Flavonoids include anthocyanins, tannins, and flavan-3-ols while the non-flavonoids consist of phenolic acids and stilbenoids (Dywer et al, 2014). Phenolic compounds act as natural antioxidants, which are beneficial to human health. Anti-oxidants have the ability to scavenge free radicals in the body, and thus decrease oxidative stress generated by reactive oxygen species (ROS) (Yao et al, 2004) (Blomhoff, 2006). This decrease in oxidative stress has been shown to prevent heart disease in humans, and exhibits anti-cancer activity (Yao et al, 2004). Due to the antioxidant nature of grape pomace, there has been considerable market potential found for the use of grape pomace phenolics in the supplement market (Dywer et al, 2014). Bioflavia is a supplemental 
powder made of dried and grounded red grape skins. The powder is sold in $300 \mathrm{~g}$ bottles and can be added to beverages such as smoothies or can be used as a substitute for yeast in various baking recipes. According to Dywer et al, the market potential of Bioflavia in 2011 was $\$ 499,273,431$ CAD.

Other studies have shown that grape seed oil can also be a suitable replacement for pork back fat in meat microemulsions, reducing fat levels from $30 \%$ to $20 \%$ (Choi et al, 2010). Grape pomace has been found to contain high amounts of extractable phenolic antioxidants as well as an economically valuable oil extracted from the seeds, which contains essential fatty acids, proteins, and non-phenolic antioxidants (Yu and Ahmedna, 2013; Dwyer et al, 2014).

With this information, it has become clear to researchers that there is significant market potential for value-added products produced from grape pomace for consumers, producers and even the environment (Dwyer et al, 2014). Consumers will obtain value added products that are marketed as a more natural/organic alternative (i.e. cooking oil), producers will reduce their carbon foot print and obtain renewable energy in the process (grape pomace in ADS) and the environment will benefit by reducing the amount of agricultural waste added to landfills (Bustamante et al, 2008).

Currently, the world's wine production and consumption is rising. Table 1 shows the total wine production and consumption worldwide and in Canada from 2011 to 2014. Worldwide, wine production and consumption both rose by a factor of $6.4 \%$ and $0.06 \%$ respectively over the 4 years. The same trend was seen in Canada from 2011 to 2014 , with an increase in both production and consumption by $23.2 \%$ and $7.66 \%$ respectively (Wine Institute 2015).

Table 1. Total Wine Production and Consumption Worldwide and in Canada from 2011 to 2014.

\begin{tabular}{llllll}
\hline Production & $\mathbf{2 0 1 1}$ & $\mathbf{2 0 1 2}$ & $\mathbf{2 0 1 3}$ & $\mathbf{2 0 1 4}$ & \% Change \\
\hline Canada & 56,000 & 65,500 & 67,000 & 69,000 & 23.2 \\
Worldwide & $26,543,800$ & $27,629,000$ & $27,885,400$ & $28,230,400$ & 6.4 \\
Consumption & $\mathbf{2 0 1 1}$ & $\mathbf{2 0 1 2}$ & $\mathbf{2 0 1 3}$ & $\mathbf{2 0 1 4}$ & \% Change \\
Canada & 470,000 & 488,000 & 498,000 & 506,000 & 7.66 \\
Worldwide & $24,686,245$ & $24,945,409$ & $24,579,072$ & $24,701,440$ & 0.06 \\
\hline
\end{tabular}

Source: Wine Institute, 2015

The significant increase in wine production since 2011 has in turn, caused an increase in the amount of grape pomace being produced and sent to landfills. According to Dywer et al, grape pomace accounts for approximately 20\%-30\% of the total grape mass prior to juice extraction (Dywer et al, 2014). Therefore based on this approximation, an estimated total mass of grape pomace produced by a winery or country can be calculated by multiplying the total grape mass by $25 \%$.

\subsection{Microemulsions}

Microemulsions have recently become an important topic in the areas of food additives, cosmeceuticals and pharmaceuticals. Microemulsions are a category of emulsions that combine water and oil together with a surfactant, used to combine two or more liquids that are normally immiscible and create a stable solution (Danielsson and Lindman, 1981). In a microemulsion, one liquid is dispersed within the other (water in oil, or oil in water) in the form of droplets at sizes less than $100 \mathrm{~nm}$ (Mason et al, 2006). According to IUPAC, the entities that are being dispersed in a microemulsion must be stabilized by a surfactant. As will be discussed later in this paper, the uses of microemulsions have led to significant improvements in the food, cosmeceutical and pharmaceutical industries.

Many foods in the food industry have been defined as emulsions and microemulsions for decades. Popular foods such as mayonnaise, salad dressings, sauces, milk and many different desserts are all defined as emulsions. Without the addition of surfactants to these foods, their individual liquids would separate and the consumption and use of these foods would become impractical (McClements, 2016). Originally, natural surfactants were used to produce these emulsions using compounds such as lecithin found in egg yolks, and various proteins found in milk. However, recent research in the areas of Food Science has lead researchers and food production companies to begin using synthetic surfactants such as sorbitan esters and sucrose esters (Kralova and Sjoblom, 2009). Although these synthetic compounds are safe for human consumption, there is always a demand from consumers 
for a more "natural" ingredient list in their foods. This demand can be met by using the natural by-product of wine making (grape pomace) as a natural surfactant to produce microemulsions.

The cosmeceutical industry has also seen many changes due to microemulsions in their products. Microemulsions have seen increasing popularity for cosmeceutical manufacturers in the production of moisturizing creams, sunscreens, antiperspirants, body gels, and various hair care products (Azeem et al, 2008). Microemulsions have the ability to drastically increase the efficiency of these cosmeceutical products and also increase their stability (Boonme, 2007). This is due to the fact that microemulsions are capable of solubilizing both hydro and lipophilic ingredients (Azeem et al, 2008), in turn broadening the spectrum of useable ingredients.

The phenolics and oil present in grape pomace can be used to create "edible microemulsions" that can serve as colloidal networks in the delivery of lipophilic (lipid-soluble) or hydrophilic (water-soluble) molecules. Microemulsions are a distinctive class of colloids and are comprised of stable dispersions of water-in-oil or oil-in-water with commonly added surfactants and co-surfactants (Sim, Han and Huang, 2009; Amiri-Rigi and Abbasi, 2016) that have the capacity to increase the stability and solubility of foods over a longer period than ordinary emulsions (particle size $>100 \mathrm{~nm})$ given their small particle size $(<100 \mathrm{~nm})$ and high degree of diffusion (Sim, Han and Huang, 2009).

Finally, the pharmaceutical industry has benefited greatly from the use of microemulsions in their drug formulations. Researchers have found that microemulsions have a significant appeal for their use as drug delivery systems. A current problem that the health care industry is facing is the delivery of hydrophobic drugs (Date and Nagarsenker, 2008). Microemulsions can be applied to drug delivery systems for both topical and oral delivery methods. Oral drug delivery has been found to improve significantly through the use of microemulsions by increasing the oral bioavailability of drugs. The microemulsion systems have been found to protect the drug molecules from the proteolytic environment of the intestine which increases the amount of drug reaching a patient's blood circulation (Lawrence, 1996).

Since the goal of this paper is to calculate the market potential of a grape pomace based microemulsion, we now turn to a description of how market potential is calculated.

\section{Research and Methodology}

In order to estimate market potential, one mass of grape pomace must be used in every calculation. 1700 tonnes of grape pomace is the mass that is being used in this paper. This value comes from a greenhouse company in southern Ontario that receives grape pomace for use in their anaerobic digestion system. This value can be scaled up and down to represent a specific company or a country as a whole.

\subsection{Microemulsion as a Cosmeceutical Raw Ingredient}

According to the United Sates Food and Drug Association, a cosmeceutical is a term used in the cosmetics industry to describe cosmetic products that have "medicinal or drug-like" benefits (U.S. Department of Health and Human Services, 2014). However it must be noted that the term cosmeceutical is not recognized by the Federal Food, Drug and Cosmetic Act.

Using a grape pomace microemulsion for cosmeceutical raw ingredients is useful for multiple reasons. According to De Porto et al (2013), grape seed oil used in the microemulsion is primarily linoleic acid, accounting for $71.965 \%$ of the oil. Linoleic acid exhibits many favourable properties for use in cosmetic face creams. Linoleic acid, when incorporated into natural face cream oils has been found to display effective anti-aging properties such as anti-inflammatory effects, acne reduction and moisture retention. According to Letawe et al (1998), after a 1-month trial period, topically applying linoleic acid to face acne provided a decrease of said acne by approximately 25\%. The American Academy of Dermatology conducted a 16-week research project to observe the effects of conjugated linoleic acid on photoaged skin. In all trials, the linoleic acid based cream was found to greatly decrease the visual effects of photo damaged skin (Hawkins et al, 2007).

The purpose of this paper is to determine the market potential of our microemulsion as a cosmeceutical raw ingredient. In order to do this, the current market for cosmeceutical raw ingredients was investigated to obtain an average unit price. Three separate calculations were performed (small, medium and large quantity) since the unit price of the ingredients decreased as the unit volume increased (i.e. customers who purchase larger volumes of ingredients will pay less on a volume basis). 
Table 2. Market potential of grape pomace microemulsion as a cosmeceutical raw ingredient

\begin{tabular}{lll}
\hline Grape pomace (tonnes) & 1700 & \\
Pomace Seeds (tonnes) & 234.056 & \\
Pomace Seed Oil (tonnes) & 38.151128 & \\
Pomace Seed Oil (mL) & 41468617.40 & \\
& Small Quantity & $1,733,976.87$ \\
Market Potential (\$ CAD) & Medium Quantity & $838,044.25$ \\
& Large Quantity & $619,608.58$ \\
\hline
\end{tabular}

Source: Bayview Flowers Ltd. (2016).

The calculations to determine the grape pomace component masses (seeds and oil) were based on the calculations performed by Dwyer et al (2014). On average, seeds account for $13.768 \%$ of the total mass of grape pomace and assuming total and complete extraction, $16.3 \%$ of the seed's mass is seed oil. The market potential was then determined for the three unit sizes based on the average prices for cosmeceutical microemulsion surfactants. These prices were obtained from the United States based company Making Cosmetics ${ }^{\circledR}$. They are one of the leading retail suppliers of cosmetic raw ingredients, and are an FDA-registered and OTC licensed cGMP/FDA facility (Making Cosmetics, 2016).

Small Quantity

$$
\frac{38151128 \mathrm{~g} \text { Grape Seed Oil }}{0.92 \frac{\mathrm{g}}{\mathrm{mL}}}=41,468,617.40 \mathrm{~mL} \text { Grape Seed Oil }
$$

$(41,468,617.40 m L$ Grape Seed Oil $)(\$ 0.03218333 / m L)=\$ \mathbf{1}, \mathbf{7 3 3}, \mathbf{9 7 6} .87$ CAD

Medium Quantity

$$
\begin{gathered}
\frac{38151128 \mathrm{~g} \text { Grape Seed Oil }}{0.92 \frac{\mathrm{g}}{\mathrm{mL}}}=41,468,617.40 \mathrm{~mL} \text { Grape Seed Oil } \\
(41,468,617.40 \mathrm{~mL} \text { Grape Seed Oil })(\$ 0.46 / \mathrm{mL})=\$ \mathbf{8 3 8}, \mathbf{0 4 4} .25 \text { CAD }
\end{gathered}
$$

Large Quantity

$$
\begin{gathered}
\frac{38151128 \mathrm{~g} \text { Grape Seed Oil }}{0.92 \frac{\mathrm{g}}{\mathrm{mL}}}=41,468,617.40 \mathrm{~mL} \text { Grape Seed Oil } \\
(41,468,617.40 \mathrm{~mL} \text { Grape Seed Oil })(\$ 5.67 / \mathrm{lbs})=\$ \mathbf{6 1 9}, \mathbf{6 0 8 . 5 8} \text { CAD }
\end{gathered}
$$

\subsection{Microemulsion as a Food Additive Raw Ingredient}

The use of microemulsions and surfactants in the food industry has a large impact on the physical properties and stability of many different food products today (Mihu and Turtoi, 2011). By being able to change the surface tension of various compounds in the food industry, food companies are able to produce products such as butter, vinaigrettes, homogenized milk and mayonnaise, all of which contain two or more liquids that would normally be immiscible. With the markets for these items consistently on the rise, there has been a demand for researchers to continually find new, low-toxicity and organic food grade microemulsions (Kralova and Sjoblom, 2009). The use of a grape pomace microemulsion does a great job of addressing these new consumer demands, as it is both non-toxic and organic.

In order to calculate the market potential of this microemulsion as a food additive as opposed to a cosmeceutical, the same calculation procedure was conducted as the one in section 2.1. However, the market research was done using the average prices of food grade surfactants as opposed to cosmeceutical surfactants.

Table 3. Market potential of grape pomace microemulsion as a food additive raw ingredient

\begin{tabular}{lll} 
& Grape pomace (tonnes) & 1700 \\
& Pomace Seeds (tonnes) & 234.056 \\
& Pomace Seed Oil (tonnes) & 38.151128 \\
& Pomace Seed Oil () & 38151128 \\
& Market Potential (\$ CAD) & Small Quantity $\quad 8,581,847.61$ \\
& Large Quantity $\quad 4,554,996.57$ \\
\hline
\end{tabular}

Source: Bayview Flowers Ltd. (2016). 
The values used to determine the average unit prices for food additive surfactants were obtained from ModernistPantry.com. Modernist Pantry is a United States based company that specializes in selling modern day cooking and baking ingredients that are based on contemporary, scientific research. This means they sell ingredients such as surfactants, emulsifiers, gelation agents, $\mathrm{pH}$ buffering agents etc. Quantities were only available in two sizes; therefore only small and large quantity calculations were performed.

Small Quantity

$$
\begin{gathered}
38.151128 \text { tonnes Grape Seed Oil }=38151128 \mathrm{~g} \text { Grape Seed Oil } \\
(38151128 \mathrm{~g} \text { Grape Seed Oil })(\$ 0.173133333 / \mathrm{g})=\$ \mathbf{8}, \mathbf{5 8 1}, \mathbf{8 4 7 . 6 1} \text { CAD }
\end{gathered}
$$

Large Quantity

$$
\begin{gathered}
38.151128 \text { tonnes Grape Seed Oil }=38151128 \mathrm{~g} \text { Grape Seed Oil } \\
(38151128 \mathrm{~g} \text { Grape Seed Oil })(\$ 0.091894167 / g)=\$ \mathbf{4}, \mathbf{5 5 4}, \mathbf{9 9 6 . 5 7} \text { CAD }
\end{gathered}
$$

\subsection{Microemulsion as a Pharmaceutical Raw Ingredient}

Recently, researchers in the pharmaceutical industry have found that microemulsions are one of the most effective methods of drug delivery in comparison to other delivery media like cream and gel skin applications. A study conducted by Kumar et al in 2014 showed that microemulsions were far more successful at drug solubilization and had a much higher rate of skin permeation than the conventional topical drug applications. These microemulsions are capable of delivering a wide array of drugs including but not limited to antiviral, anti-inflammatory, antioxidant, antifungal and various local anesthetics. (Kumar et al, 2014). A large problem that currently faces the health care industry is the delivery of hydrophobic drugs. Thankfully, this problem can be overcome by using microemulsions as a mode of delivery (Date and Nagarsenker, 2008). Just like cosmeceuticals and food additives, the general public will accept the use of grape pomace as a microemulsion as it will be a sustainable, organic and non-toxic alternative to conventional microemulsions.

The calculation method was conducted in the same manner as sections 2.1 and 2.2. It must be noted that the market potential values calculated for pharmaceuticals is possibly less accurate than those of cosmeceuticals and food additives. Researching the market for frequently used surfactants and microemulsions used in pharmaceuticals proved to be difficult. Most pharmaceutical companies do not release the exact chemical make-up of their microemulsions, which makes identifying costs/prices very difficult. Therefore the values that were used to calculate an average unit price presented a much wider range, which in turn produced a wider range of market potentials for the three size quantities.

Table 4. Market potential of grape pomace microemulsion as a pharmaceutical raw ingredient

\begin{tabular}{lll}
\hline Grape pomace (tonnes) & 1700 & \\
Pomace Seeds (tonnes) & 234.056 & \\
Pomace Seed Oil (tonnes) & 38.151128 & \\
Pomace Seed Oil () & 38151128 & \\
& Small Quantity & $58,735,370,37$ \\
Market Potential (\$ CAD)) & Medium Quantity & $16,227,303.90$ \\
& Large Quantity & $11,163,115.80$ \\
\hline
\end{tabular}

Source: Bayview Flowers Ltd (2016).

Small Quantity

38.151128 tonnes Grape Seed Oil $=38151128 \mathrm{~g}$ Grape Seed Oil

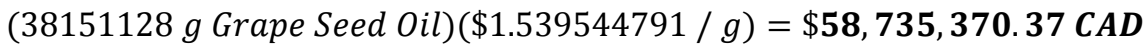

Medium Quantity

38.151128 tonnes Grape Seed Oil $=38151128 \mathrm{~g}$ Grape Seed Oil

$(38151128 \mathrm{~g}$ Grape Seed Oil $)(\$ 0.383685405 / g)=\$ \mathbf{1 6}, \mathbf{2 2 7}, \mathbf{3 0 3} .90$ CAD

Large Quantity

38.151128 tonnes Grape Seed Oil $=38151128 \mathrm{~g}$ Grape Seed Oil
$(38151128 \mathrm{~g}$ Grape Seed Oil $)(\$ 0.29260251 / \mathrm{g})=\$ \mathbf{1 1}, \mathbf{1 6 3}, \mathbf{1 1 5 . 8 0}$ CAD 


\section{Discussion}

The volume of food waste produced by both Canada and the world as a whole is increasing at an alarming rate. This increase is having a significant negative impact from both an environmental and economic perspective. With the increase in global population this pattern of increasing waste will only continue to rise, unless new sustainable projects are further pursued. By finding uses for food waste such as grape pomace, the burden on the global environment and economic industries can be decreased.

The demand for new, non-toxic and natural products amongst Canadian consumers makes grape pomace microemulsions a plausible candidate in all three industries discussed in this paper.

The market potential for grape pomace microemulsions as a cosmeceutical raw ingredient ranged from $\$ 619,608.58$ for large quantities, to $\$ 1.7$ million for small quantities. This was the lowest market potential of the 3 categories. However, the current market for cosmeceuticals could benefit from a grape pomace microemulsion. Cosmeceutical skin care products in Canada have had positive growth rates from 2010 until 2015, growing an average of $4.12 \%$ per annum. From 2010 until 2014 there was a steady decrease in the growth percentage, although positive, it decreased from $5.2 \%$ to $3.1 \%$, a difference of $2.1 \%$. However, in the past year the sales of skin care products have increased by $1.1 \%$. This drastic increase in growth of skin care products could indicate an optimum time to enter the market. According to Euromonitor, skin care products attracted $\$ 2.0$ billion in sales in 2015, with projections of upwards to $\$ 2.3$ billion in 2020. A major contributor to the skin care market is the tag line "Anti-aging" which promises to reduce the appearance of wrinkles and other age telling features. The aging population of Canada has been increasing over the past few years with baby boomers entering their later years. This is a great advantage for companies looking to sell microemulsions as they are a perfect candidate for the "anti-aging" category due to their high percentage of linoleic acid (Euromonitor, 2015).

The market potential for a grape pomace microemulsion as a food additive was $\$ 4,554,996.57$ for large quantities and $\$ 8,581,847.61$ for small quantities. This was the second highest market potential of the 3 categories that were studied. The Canadian food industry is large and is divided into many different categories. This makes it very difficult to look at the entire market as a whole; therefore individual sub-markets should be examined. The most influential food market for companies looking to sell microemulsions will most likely be the fortified and functional packaged food industry. Fortified and functional foods are products that have some form of positive health benefit associated with their consumption. The addition of grape pomace microemulsions can add positive health benefits due to its high antioxidant properties. According to Euromonitor, the market for fortified and functional foods reached $\$ 2.2$ billion in 2015 with a growth rate of $2 \%$ from the previous year. The market is expected to grow at a moderate pace and expand by $2 \%$ by 2020 . Just like cosmetics and pharmaceuticals, the market continues to grow due to an ever-increasing demand from consumers for added health benefits and more organic options. The market potential for a company's microemulsion as a food additive was as high as $\$ 8.5$ million and is the second largest market potential of the three options.

Finally, the market potential for a grape pomace microemulsion as a pharmaceutical raw ingredient was $\$ 11,163,115.80$ for large quantities and $\$ 58,735,370.37$ for small quantities. This was the highest market potential of the 3 categories that were studied. The pharmaceutical market in Canada is the largest market of the three studied in this paper. According to the Government of Canada, in 2013 Canada saw \$22.0 billion in both patented and non-patented drug sales. This value is up almost $100 \%$ since 2001, which shows that the market is continually increasing. The promising aspect of the pharmaceutical market is that it is one of the most innovative markets in Canada. There is a constant push to increase new and innovative drugs to bring to the market that will benefit both the consumer and the producer (Government of Canada, 2015). Projects such as this current study exemplify this. $89.0 \%$ of pharmaceutical sales are within the retail drug market (over the counter and prescription drugs etc.) while the other $11.0 \%$ is associated with hospitals. Fortunately, this microemulsion caters to both markets, which means a grape pomace microemulsion can be sold as a raw ingredient to the pharmaceutical producers that employ both of these distribution channels. The demand for organic non-toxic drugs increases yearly, so companies looking to produce microemulsions will be in a good position to enter this market. The market potential for pharmaceutical raw ingredients is also the highest of all three options, reaching almost $\$ 59$ million.

It must be noted that the calculations performed in this paper are hypothetical. They assume the production and sale of $100 \%$ of the original grape pomace, which is highly unlikely in a consumer market. For a company entering any three of the suggested markets, the actual revenue values would be lower. However, the purpose of this paper is to show that there is significant market potential in grape pomace, and agricultural waste in general. By investigating the uses of agriculture waste, Canada can help alleviate stresses on the environment by 
decreasing landfill usage, and companies can benefit economically by the production of value added products.

\section{Acknowledgements:}

This work was supported by Natural Sciences and Engineering Research Council of Canada (NSERC) program. Project number 499360-16. Authors thank Bayview Flowers Ltd. For providing grape pomace samples.

\section{References}

Abbasi, T., Tauseef, S. M., \& Abbasi, S. A. (2012) Biogas Energy. Springer Briefs in Environmental Science. https://doi.org/10.1007/978-1-4614-1040-9

Amiri-Rigi, A., \& Abbasi, S. (2016) Microemulsion-based lycopene extraction: Effect of surfactants, co-surfactants and pretreatments. Food Chem, 197, 1002-1007. https://doi.org/10.1016/j.foodchem.2015.11.077

Azeem, A., Rizwan, M., Ahmad, F. J., Khan, Z. I., Khar, R. K., Aqil, M., \& Talegaonkar, S. (November 2008) Emerging Role of Microemulsions in Cosmetics. Recent Patents on Drug Delivery \& Formulation, 15, 275-289. https://doi.org/10.2174/187221108786241624

Bayview Flowers Ltd. (communication with R\&D division), Jordan Station, ON. www.bayviewflowers.com

Benjamin, S., \& Spener, F. (2009). Conjugated linoleic acids as functional food: an insight into their health benefits. Nutrition and Metabolism, 6, 36. https://doi.org/10.1186/1743-7075-6-36

Blomhoff, R., Carlsen, M. H., Andersen, L. F., \& Jacobs, D. R. (2006). Health Benefits of nuts: potential role of antioxidants. British Journal of Nutrition, 96, S52-S60. https://doi.org/10.1017/BJN20061864

Boonme, P. (2007) Applications of microemulsions in cosmetics. Journal of Cosmetic Dermatology, 6, 223-228. https://doi.org/10.1111/j.1473-2165.2007.00337.x

Bouallagui, H., Touhami, Y., Cheikh, R. B., \& Hamdi, M. (May 2005). Bioreactor Performance in Anaerobic Digestion of Fruit and Vegetable Wastes.

Bustamante, M. A., Moral, R., Paredes, C., Pérez-Espinosa, A., Moreno-Caselles, J., \& Pérez-Murcia, M. D. (2008). Agrochemical characterisation of the solid by-products andresidues from the winery and distillery industry. Waste Management, 28(2), 372-380. https://doi.org/10.1016/j.wasman.2007.01.013

Carlsson, M., Lagerkvist, A., \& Morgan-Sagastume, F. (2012). The effects of substrate pre-treatment on anaerobic digestion systems: A review. Waste Management, 32(9), 1634-1650. https://doi.org/10.1016/j.wasman.2012.04.016

Da Porto, C., Porretto, E., \& Decorti, D. (2013). Comparison of ultrasound-assisted extraction with conventional extraction methods of oil and polyphenols from grape (Vitisvinifera L.) seeds. Ultrasonics Sonochemistry, 20, 1076-1080. https://doi.org/10.1016/j.ultsonch.2012.12.002

Dai, W., Xu, X., Liu, B., \& Yang, F. (November 2015). Toward energy-neutral wastewater treatment: A membrane combined process of anaerobic digestion and nitritation-anammox for biogas recovery and nitrogen removal. Chemical Engineering Journal, 279, 725-734. https://doi.org/10.1016/j.cej.2015.05.036

Danielsson, I., \& Lindman, B. (December 1981). The definition of microemulsion. Colloids and Surfaces, 3(4), 391-392. https://doi.org/10.1016/0166-6622(81)80064-9

Date, A. A., \& Nagarsenker, M. S. (May 2008). Parenteral microemulsions: An Overview. International Journal of Pharmaceutics, 355(1-2), 19-30. https://doi.org/10.1016/j.ijpharm.2008.01.004

Duba, K. S., \& Fiori, L. (March 2015). Supercritical $\mathrm{CO}_{2}$ extraction of grape seed oil: Effect of process parameters on the extraction kinetics. The Journal of Supercritical Fluids, 98, 33-43. https://doi.org/10.1016/j.supflu.2014.12.021

Dwyer, K., Hosseinian, F., \& Rod, M. (2014). The Market Potential of Grape Waste Alternatives. Journal of Food Research, 3(2), 91-106. https://doi.org/10.5539/jfr.v3n2p91

Euromonitor. (April 2016). Fortified/Functional Packaged Food in Canada. Passport. Retrieved from: http://www.portal.euromonitor.com.proxy.library.carleton.ca/portal/analysis/tab

Euromonitor. (April 2016). Skin Care in Canada. Passport. Retrieved from: http://www.portal.euromonitor.com.proxy.library.carleton.ca/portal/analysis/tab

Food and Agriculture Organization of the United Nations. (September 2009). 2050: A third more mouths to feed. Retrieved from: http://www.fao.org/news/story/en/item/35571/icode/ 
Gooch, M. V., Felfel, A., \& Glasbey C. (December 2014). \$27 Billion Revisited The cost of Canada's Annual Food Waste. Value Chain Management International.

Government of Canada. (January 2015). Pharmaceutical Industry Profile. Innovation, Science and Economic Development Canada. Retrieved from: https://www.ic.gc.ca/eic/site/lsg-pdsv.nsf/eng/h_hn01703.html

Kim, J. K., Kim, Y., Kim, Y. J., \& Park, Y. (2016). Conjugated Linoleic Acid: Potential health benefits as a functional food ingredient. Annual Review of Food Science and Technology, 7, 221-244. https://doi.org/10.1146/annurev-food-041715-033028

Kralova, I., Sjoblom, J. (September 2009). Surfactants Used in Food Industry: A Review. Journal of Dispersion Science and Technology, 30(9), 1363-1383. https://doi.org/10.1080/01932690902735561

Kumar, A., Kushwaha, V., Sharma, P. K. (March 2014). Pharmaceutical Microemulsion: Formulation, Characterization and Drug deliveries across skin. International Journal of Drug Development and Research, 6(1), 1-21.

Lawrence, M. J. (1996). Microemulsions as drug delivery vehicles. Dynamic aspects of colloids \& interfaces. 1:826-832. https://doi.org/10.1016/s1359-0294(96)80087-2

Lawrence, M. J., Rees, G. D. (December 2000). Microemulsion-based media as novel drug delivery systems. Advanced Drug Delivery Reviews, 45(1), 89-121. https://doi.org/10.1016/S0169-409X(00)00103-4

Letawe, C., Boone, M., \& Pierard, G. E (March 1998). Digital image analysis of the effect of topically applied linoleic acid on acne microcomedones. Clinical \& Experimental Dermatology, 23(2), 56-58. https://doi.org/10.1046/j.1365-2230.1998.00315.x

Masaki, H. (2010) Role of antioxidants in the skin: Anti-aging effects. Journal of Dermatological Science, 58, 85-90. https://doi.org/10.1016/j.jdermsci.2010.03.003

Mason, T. G., Wilking, J. N., Meleson, K., Chang, C. B., \& Graves, S. M. (2006). Nanoemulsions: formation, structure, and physical properties. Journal of Physics: Condensed Matter, 18, 635-666. https://doi.org/10.1088/0953-8984/18/41/r01

McClements, D. J. (August, 2015). Food Emulsions: Principles, Practises and Techniques. $3^{\text {rd }}$ Edition. Boca Raton, Florida. CRC Press.

Mihu, G. C., \& Turtoi, M. (March 2011). Use of microemulsions in food industry. Paper of the Sibiu Alma Mater University Conference. Fifth Edition, 1, 361-368.

Mlikoglu, M., Lin, C. S. K., \& Webb, C. (June 2013) Analysing global food waste problem: Pinpointing the facts and estimating the energy content. Central European Journal of Engineering, 3(2), 157-164. https://doi.org/10.2478/s13531-012-0058-5

Parfitt, J., Barthel, M., \& Macnaughton, S. (August 2010). Food waste within food supply chains: quantification and potential for change to 2050. Philosophical Transactions of The Royal Society B., 365(1554), 3065-3081. https://doi.org/10.1098/rstb.2010.0126

Perumalla, A. V. S., Hettiarachchy, N. S. (May 2011). Green tea and grape seed extracts - Potential applications in food safety and quality. Food Research International, 44(4), 827-839.

https://doi.org/10.1016/j.foodres.2011.01.022

Sephora. (2016). Retrieved from: http://www.sephora.com/search/search.jsp?keyword=grape\%20seed\%20oil\&mode=all

Sim, W. L., Han, M. Y., \& Huang, D. (2009). Quantification of antioxidant capacity in a microemulsion system: synergistic effects of chlorogenic acid with alpha-tocopherol. J Agric Food Chem, 57, 3409-3414. https://doi.org/10.1021/jf8040484

U.S. Department of Health and Human Services (2014). "Cosmeceutical" Retrieved from: http://www.fda.gov/Cosmetics/Labeling/Claims/ucm127064.htm

Ulta Beauty. (2016). Retrieved from: http://www.ulta.com/ulta/a/_/Ntt-grape\%20seed\%20oil/Nty-1?Dy=1\&ciSelector=searchResults

Wine Institute. (2012). Statistics. Retrieved from: https://www.wineinstitute.org/resources/statistics

Yao, L. H., Jiang Y. M., Shi, J., Tomas-Barberan, F. A., Datta, N., Singanusong, R., \& Chen S. S. (July 2004). Flavonoids in Food and Their Health Benefits. Plant Foods for Human Nutrition, 59(1), 113-122. https://doi.org/10.1007/s11130-004-0049-7 
Yu, J., \& Ahmedna, M. (2013). Functional components of grape pomace: their composition, biological properties and potential applications. International Journal of Food Science and Technology. 48(2), 221-237. https://doi.org/10.1111/j.1365-2621.2012.03197.x

\section{Copyrights}

Copyright for this article is retained by the author(s), with first publication rights granted to the journal.

This is an open-access article distributed under the terms and conditions of the Creative Commons Attribution license (http://creativecommons.org/licenses/by/4.0/). 